\title{
Aspergillus but Not Candida: Fatal Fungus Infection in Critical COVID-19 Patients
}

\author{
Aifang Zhong ${ }^{1}$, Yang Yang ${ }^{1}$, Jiang $\mathrm{Wu}^{1}$, Lei Xiong ${ }^{1}$, Jian $\mathrm{Wu}^{1}$, Jiawei Shen ${ }^{1}$, Wei Dai ${ }^{1}$, \\ Tao Luo ${ }^{1}$, Yanju Guo ${ }^{1}$, Jun Zhao ${ }^{1}$, Ying $\mathrm{Han}^{1}$, Peiran Zhu ${ }^{1}$, Qiuyue $\mathrm{Wu}^{1}$, Weiwei $\mathrm{Li}^{1}$, \\ Changjun Wang ${ }^{2}$, Li Han ${ }^{2}$, and Xinyi Xia ${ }^{1}$ \\ ${ }^{1}$ Nanjing Jinling Hospital \\ ${ }^{2}$ Center for Disease Control and Prevention of PLA
}

October 28, 2020

\begin{abstract}
Abstract Objectives: Earlier researches suggested patients should be routinely screened for bacteria and fungi infection after COVID-19 being confirmed. Here, we enrolled 236 patients with COVID-19 to analyze the clinical characteristics, fungal strains, mortality, and laboratory data of different groups. Design: Single center retrospective study Patients: A total of 236 COVID-19 patients from Huoshenshan Hospital were included in this study, consisting of 14(6\%) died cases, 222(94\%) discharged cases . Results: The result revealed that 5 mortality in positive group were all related to aspergillus infection while candida infection rarely caused death. Aspergillus was most common in non-survivors while candida was most common in survivors. In terms of interleukin-6 (IL6), viral loads, nucleic acid clearance time, etc, fungal serologically positive group had a higher level than negative group. Conclusions: Non-survivors of Covid-19 with fungal infection were almost associated with aspergillus infection. Aspergillus infection, instead of candida infection might be fatal for critical ill patients with COVID-19. There is great significance to carry out routine screening for fungal infection especially for critical patients to enable early treatment to be implemented. Keywords: coronavirus disease 2019 (COVID-19); fungal infection; aspergillus; mortality
\end{abstract}

\section{Introduction}

The coronavirus disease (COVID-19) broke out in December 2019 and spread worldwide with an efficient person-to-person transmission rate $(\mathrm{R} 0)^{1}$, has caused more than 780,000 deaths until August 21, 2020². Epidemiological and clinical characteristics have been described in earlier researches, and some researchers suggested patients should be routinely screened for bacteria and fungi infection after COVID-19 being confirmed $^{3}$. Chen Nanshan described fungal infection with COVID-19 firstly, the incidence of fungal infection was $4 \%$, higher than bacterial infection $1 \%{ }^{4}$. Similarly, during the fight against SARS in 2002-03, fungal co-infection with Severe Acute Respiratory Syndromes (SARS) was repeatedly reported to significantly increased mortality ${ }^{5}$. Fungal infection among COVID-19 patients especially severe and critical patients is a noteworthy problem, but so far, fungal infections during COVID-19 are still rarely reported and may be underdiagnosed.

This study was conducted to analyze clinical characteristics between fungal serologically positive and negative group, categorize the fungal strains and mortality of different clinical levels. We hope our findings will inform other countries of the problem of COVID-19 with invasive fungal infection especially aspergillus infection and improve the prognosis of patients.

\section{Methods}

\section{Data Collection}


A total of 236 patients with COVID-19 from Wuhan Huoshenshan Hospital were enrolled in this study, from Jan 4 to March 30, 2020. All COVID-19 patients were defined according to the diagnostic and treatment guideline for SARS-CoV-2 issued by Chinese National Health Committee (Version 3-7) ${ }^{6}$ and confirmed by the SARS-CoV-2 viral nucleic acid detection using real-time reverse-transcriptase polymerase-chain-reaction (RT-PCR) assay.

All data, including baseline information, laboratory examination, nucleic acid test results, and imaging data were obtained from the hospital electronic records. Host factors and treatment factors of fungal infection were referred to the European Organization for Research and Treatment of Cancer and the Mycoses Study Group Education and Research Consortium (EORTC/MSGERC) consensus definitions of invasive fungal diseases (IFDs) ${ }^{7}$. The single cell sequence RNA database including eight healthy lungs were downloaded from GSE122960 on GEO website (https://www.ncbi.nlm.nih.gov/geo/), R language (version 3.2.5) and CellMarker (http://biocc.hrbmu.edu.cn/CellMarker/search.jsp?quickSearchInfo=GZMB) were used for subsequent database analysis.

\section{Serological identification}

Five serological identification included detection of aspergillus galactomannan (GM test), candida mannan (MN test), IgG antibody to aspergillus thioredoxin reductase (Atr- IgG), IgG antibody to enolase (Eno-IgG), and glucuronoxylomannan (GXM) to cryptococcus neoformans, which were supplied by Danna (Danna,Tianjin,China).

\section{Fungus culture}

The instrument and material included CHROMagar candida media, fungus drug sensitivity kit (ATB Fungu 3), ATB turbidimeter, etc.

\section{Fungus chip}

Common clinical fungi was detected by Boao chips for complicated infection detection (isothermal ampilification on disk chip-ZJ) following the manufacture's instructions (Boao, Chengdu, China). There were a total of 20 indicators, including candida, aspergillus, cryptococcus neoformans, trichoderma, pneumocystis, etc.

\section{Laboratory indicators detection assay}

Many laboratory indicators in plasma of participants were detected with chemiluminescent immunoassay (CLIA) based on the SAL 9000 Modular System with the CLIA kit, which was supplied by Shenzhen Mindray Bio-Medical Electronics Co., Ltd.( Shenzhen, China).

\section{Serum anti-SARS-CoV-2 antibodies assay}

Total SARS-CoV-2 IgM or IgG in the serum was measured by chemiluminescence using commercially available kits (Shenzhen YHLO Biotech Co., Ltd.). The magnetic beads of this kit are coated with recombinant $\mathrm{N}$ and $\mathrm{S}$ proteins. S-, RBD-, and $\mathrm{N}$-specific IgM and IgG levels were tested by chemiluminescence using commercially available kits (Nanjing RealMind Biotech Co., Ltd.).

\section{Statistical analysis}

For continuous variables, the median and interquartile range (IQR) were used to show the distribution, differences were analyzed by the Wilcoxon rank-sum test. For categorical variables, the number and percentage were used to show, differences were analyzed by the chi-square test. When the data did not meet the chi-square test, Fisher's exact test was adopted. A p value less than 0.05 was considered statistically significant. We used SPSS (version 26.0) for all analysis.

\section{Results}

\section{Baseline characteristics of patients}


Based on serological experiment results, 236 patients were divided into serologically positive group including $80(34 \%)$ patients and serologically negative group including $156(66 \%)$ patients (Table 1). The age of patients appeared a statistically significant difference between two groups ([?]65 years; positive, $\mathrm{n}=35,44 \%$; negative, $\mathrm{n}=10,6 \%$ ). There was no significant difference in clinical level between the two groups, however, proportion of positive patients in moderate, severe, critical levels increased gradually $(29 \%, 34 \%, 37 \%$, respectively, Figure 1A). Among host factors, solid tumor (positive, $\mathrm{n}=8,10 \%$; negative, $\mathrm{n}=12,8 \%$ ) and history of invasive fungal infection (positive, $n=2,3 \%$; negative, $n=1,1 \%$ ) had a slight but not significant lift in positive group than negative group (Table 1). Among treatment factors, broad-spectrum antibiotics therapy had a significant difference (positive, $\mathrm{n}=23,29 \%$; negative, $\mathrm{n}=24,15 \%$ ), other factors including glucocorticoids therapy (positive, $\mathrm{n}=14,18 \%$; negative, $\mathrm{n}=18,12 \%$ ), central venous cannula (positive, $\mathrm{n}=10$, $13 \%$; negative, $\mathrm{n}=12,8 \%$ ), invasive ventilator (positive, $\mathrm{n}=8,10 \%$; negative, $\mathrm{n}=13,8 \%$ ), and ICU admission (positive, $\mathrm{n}=16,20 \%$; negative, $\mathrm{n}=28,18 \%$ ) had a slight but not significant lift in positive group than negative group. Deaths of two groups had a same proportion (positive, $n=5,6 \%$; negative, $n=9,6 \%$ ).

\section{Strains and mortality of fungal co-infection}

We further calculated fungal strains and mortality of moderate, severe, and critical patients. Fungal strains were divided into three categories, including only candida, only aspergillus, candida with aspergillus. Only candida had $32(14 \%)$ cases, and there was significant difference in moderate, severe, critical levels $(7 \%, 15 \%$, $2 \%$, respectively, p-value $<0.05$, Table 2$)$. Only aspergillus had $31(13 \%)$ cases which was similar to only candida, and there were 4 (14\%), 21 (14\%), 6 (11\%) cases in moderate, severe, critical levels, respectively. Candida with aspergillus had $17(7 \%)$ cases, and there was significant difference in moderate, severe, critical levels $(7 \%, 6 \%, 22 \%$, respectively, p-value $<0.01$, Table 2$)$.

Of note, survivors were most associated with candida infection while non-survivors were with aspergillus infection (Table 2 and Figure 1C). Among a total of 5 mortality in positive cases, there was no mortality in only candida infection while the 5 mortality were all related to aspergillus infection, including 4 cases of only aspergillus infection and 1 case of candida with aspergillus co-infection (Table 2). Additionally, autopsy of one critical patient revealed pulmonary aspergillus infection. In a word, aspergillus, rather than candida, is probably the real pathogenic fungus, and aspergillus infection might be a non-negligible risk factor for death of critical patients.

After screening from 3059 patients, 25 patients were found to receive the treatment with anti-fungal drugs including caspofungin, fluconazole and voriconazole (Figure 2A). Voriconazole is for candida infection while caspofungin and fluconazole are for aspergillus infection. According to six-category scale score standards, most of them scored five which means a hospitalization with ECMO and/or mechanical ventilation (Figure 2B), therefore, theses patients received prophylactic/empirical anti-fungal therapy for clinical consideration.

Positive rate comparison of different methods were shown in Supplementary Table 1. Suspicious positive rate of fungus culture was the highest because of a high false positive rate, followed by Atr-IgG test, Eno-IgG test, fungus chip, candida mannan test and GM test $(47 \%, 18 \%, 17 \%, 16 \%, 8 \%, 6 \%$, respectively).

\section{Laboratory indicators results}

Laboratory indicators were retrieved and systematically compared between positive and negative groups. White blood cell count, neutrophil absolute value, eosinophil absolute value, basophil absolute value, procalcitonin, hypersensitive c-reactive protein, total protein, blood glucose showed a higher value in positive group, however, without significant differences. Interleukin-6 in positive group was significantly higher than negative group (p-value $<0.05$, Figure 3D). Lymphocyte was roughly equal between two groups (Figure 3E).

\section{Nucleic acid test results}

The proportion of positive nucleic acid test results was higher in the positive group than negative group (28\% vs $21 \%$, p-value $=0.28$, Figure $3 \mathrm{~A}$ ). Ct (cycle threshold) value was less in the positive group than negative group, which was more pronounced among severe and critical patients, indicating that positive patients might have more viral RNA loads (Figure 3B). Nucleic acid clearance time was longer in positive group than 
negative group among moderate patients, while it was shorter among severe and critical patients (Figure 3C), possibly due to the virus has entered the lower respiratory tract and blood, making it difficult to detect nucleic acid in throat swabs collected in the upper respiratory tract.

\section{Antibody test results}

We compared total antibody and specific antibody respectively. Total IgG in positive group was slightly higher than negative group. Total IgM was higher in positive group than negative group among moderate patients while lower among severe and critical patients. S-IgG was lower in positive group than negative group due to $\mathrm{S}-\operatorname{IgG}$ is a protective antibody. RBD-IgG was lower in positive group than negative group among severe and critical patients. N-IgG in positive group was higher than negative group on account of N-IgG is an antibody related to immunogenicity and there was a stronger immune response in positive group. However, there was no significant difference in antibody data (Figure 4).

\section{Chest CT of three patients with fungal infection}

Case 1: chest CT was obtained on Feb 17 (Figure 5.1A, 1B). Male, 86 years old, whose Eno-IgG test and fungus culture presented positive results. Patchy and fragmentary flocculent density increased shadows were observed in both lungs, some of which showed ground-glass changes. Irregular nodules were observed in the right upper lung, with eccentric cavity inside and long cable shadow around the nodules. The trachea and main bronchi were unobtrusive.Multiple calcifications were seen in the aorta and coronary arteries, the pulmonary artery and the heart were enlarged. Curved effusion was seen in the thorax on both sides.

Case 2: chest CT obtained on Mar 6 (Figure 5. 2A, 2B). Male, 81 years old, whose Atr-IgG test presented two continuous positive results, and received the treatment of antifungal drug voriconazole.Multiple flaky, cable shadows were scattered in both lungs. Tracheobronchial patency, aortic arch and coronary calcification.Irregular nodules were seen under the right lower lung pleura, surrounded by ground glass shadow and long cable shadow, and air bronchus shadow inside. There was no obvious thickening of bilateral pleura and no accumulation of fluid density shadow in bilateral thorax.

Case 3: chest CT obtained on Mar 19 (Figure 5. 3A, 3B). Female, 85 years old, two CT examinations in other hospital indicated the possibility of mould pellets. The clinical suspected presence of aspergillus infection, and fever and chest tightness of patient have improved after taking oral treatment of antifungal drug voriconazole. Double lung fields were clear, right upper appeared lung bronchus dilates, and irregular nodules were seen, in which there was an air crescent sign, a clear border of nodules, surrounded by long cable shadow. The right lung showed a few pieces of flocculent density increased shadow and a ground-glass change. Right pleural presented a calcification, no pleural effusion.

\section{Mechanisms and entry receptors of aspergillus in lungs}

Many important human pathogens either recruit host actin binding proteins, or directly interact with $\operatorname{actin}^{8-10}$. Recruiting host actin nucleating proteins such as Arp2/3 complex to motivate actin-dependent endocytosis or active penetration has been recognized as a main mechanism for explaining the aspergillus invasion of epithelial cells ${ }^{11}$. Other mechanisms include aspergillus CalA binds to integrin $\alpha 5 \beta 1$ and mediates host cell invasion, RAB5C, RAB7 $\mathrm{A}^{12}$, and $\mathrm{WIPF} 2{ }^{13}$ mediate the internalization of conidia into epithelial cells. Accordingly, WIPF2, RAB5C, RAB7A, ITGA5, ITGB1, APPC2, ARPC3, ARPC4, ARPC5 were selected and analyzed in a GEO database including eight healthy donors. These genes appeared a higher expression among the old than young people, and ARPC2 has a most expression mainly in cancer stem cell, lung epithelial cell, basal cell, and secretory cell (Figure 6A). RAB7A, ARPC3 and ARPC5 in macrophage showed a higher expression among females than males, RAB5C and ARPC4 are the opposite. There is no significant difference in other cells between males and females (Figure 6B).

\section{Discussion}

Earlier studies have suggested that patients with severe virus infection tend to develop invasive fungal infection including candidia, aspergillus, cryptococcus neoformans, pneumocystis which was associated with 
high mortality ${ }^{14-16}$. According to our study, there was no significant difference in mortality between fungal positive and negative groups, however, it is noteworthy that 5 mortality in positive group were all related to aspergillus infection while candida infection rarely caused death, autopsy result of one critical patient also showed aspergillus infection. Aspergillus was more common in non-survivors while candida was more common in survivors since the presence of colonization candida. COVID-19 patients who received repeated broadspectrum antibiotics therapy, invasive ventilation, etc, should be aware of the risk of fungal infection due to they having high risk factors for the development of invasive fungal infection ${ }^{17-20}$, and the use of antibiotics, invasive ventilators and corticosteroids in critical patients was more often than non-critical patients ${ }^{3-4,21}$, which may increase the risk of invasive fungal infection in critical patients.

Among laboratory indicators, interleukin-6 was significantly higher in positive group. Though white blood cell count, neutrophil absolute value, procalcitonin, blood glucose, etc, showed a higher value in positive group, there was no significant difference. Procalcitonin was elevated in patients suffering from bacterial and fungal infections and magnitude of values was associated with the severity of the infection ${ }^{22-23}$. People with high blood sugar and diabetes are more likely to have fungal infections ${ }^{24,7}$. In addition, positive group tend to have more viral RNA loads and longer virus clearance time than negative group. In short, laboratory indicators, nucleic acid and antibodies are hardly to have diagnostic significance in fungal infection, and pathological tissue sections should be taken as the gold standard as invasive fungal infection. However, due to the particularity and urgency of this epidemic, histopathological method was not performed at that moment.

In terms of methodology, combination of serological antibody and antigen detection for fungal infection (candida mannan and Eno-IgG, GM and Atr-IgG) is still necessary, which can improve diagnostic specificity and sensitivity of candida infection ${ }^{25}$ and aspergillus infection ${ }^{26}$.

\section{Conclusion}

Aspergillus infection, instead of candida infection might be fatal for critical ill patients with COVID-19, which poses a threat to the wide range population at present. There is need to carry out a specific and rapid diagnostic test for invasive fungal infection especially for critical patients to enable early treatment to be implemented, antifungal chemoprophylaxis and environmental measures could also be envisaged with the aim to decrease morbidity and mortality.

\section{Author contributions}

AZ conducted study design; YY wrote the manuscript; JW, LX, and other people contributed with comments during the writing; JW conducted data analysis; XX conceived the study.

\section{Funding}

This study was financially supported by grants Key Foundation of Wuhan Huoshenshan Hospital(2020[18]), Key Research\& Development Program of Jiangsu Province(BE2018713), Medical Innovation Project of Logistics Service(18JS005)

\section{Ethical approval}

This study was approved by the Medical Ethical Committee of Wuhan Huoshenshan Hospital (No. HSSLL011). Written informed consent was obtained from each patient.

\section{Acknowledgments}

We thank all the patients who consented to donate their data for analysis and all the medical staff members of Huoshengshan hospital. We would also thank the editor and peer reviewers for their hard work for this article.

\section{Conflicts of interest}

We declare no competing interests. 


\section{Reference}

1. Li Q, Guan X, Wu P, et al. Early transmission dynamics in Wuhan, China, of novel coronavirus-infected pneumonia. New England Journal of Medicine. 2020.

2. Organization WH. Coronavirus disease (COVID-19) situation dashboard. Website https://who sprinklr com [accessed 21 August 2020]. 2020.

3. Huang C, Wang Y, Li X, et al. Clinical features of patients infected with 2019 novel coronavirus in Wuhan, China. The lancet. 2020;395(10223):497-506.

4. Chen N, Zhou M, Dong X, et al. Epidemiological and clinical characteristics of 99 cases of 2019 novel coronavirus pneumonia in Wuhan, China: a descriptive study. The Lancet. 2020;395(10223):507-513.

5. Organization WH. Clinical management of severe acute respiratory infection when novel coronavirus (2019-nCoV) infection is suspected: interim guidance. In: Clinical management of severe acute respiratory infection when novel coronavirus (2019-nCoV) infection is suspected: Interim guidance.2020:21-21.

6. Commission CNH. Chinese Clinical Guidance for COVID-19 Pneumonia Diagnosis and Treatment [Internet]. In:2020.

7. Donnelly JP, Chen SC, Kauffman CA, et al. Revision and update of the consensus definitions of invasive fungal disease from the European Organization for Research and Treatment of Cancer and the Mycoses Study Group Education and Research Consortium. Clinical Infectious Diseases. 2019.

8. Cossart P, Sansonetti P J. Bacterial invasion: the paradigms of enteroinvasive pathogens $[\mathrm{J}]$. Science, 2004,304(5668):242-248.

9. Sheehan K B, Martin M, Lesser C F, et al. Identification and Characterization of a Candidate Wolbachia pipientis Type IV Effector That Interacts with the Actin Cytoskeleton[J]. mBio, 2016,7(4).

10. Bugalhao J N, Mota L J, Franco I S. Identification of regions within the Legionella pneumophila VipA effector protein involved in actin binding and polymerization and in interference with eukaryotic organelle trafficking[J]. Microbiologyopen, 2016,5(1):118-133.

11. Yang W, Yan L, Wu C, et al. Fungal invasion of epithelial cells[J]. Microbiol Res, 2014,169(11):803-810.

12. Clark H R, Powell A B, Simmons K A, et al. Endocytic Markers Associated with the Internalization and Processing of Aspergillus fumigatus Conidia by BEAS-2B Cells[J]. mSphere, 2019,4(1).

13. Culibrk L, Croft C A, Toor A, et al. Phagocytosis of Aspergillus fumigatus by Human Bronchial Epithelial Cells Is Mediated by the Arp2/3 Complex and WIPF2[J]. Front Cell Infect Microbiol, 2019,9:16.

14. Schauwvlieghe AF, Rijnders BJ, Philips N, et al. Invasive aspergillosis in patients admitted to the intensive care unit with severe influenza: a retrospective cohort study. The Lancet Respiratory Medicine. 2018;6(10):782-792.

15. Wauters J, Baar I, Meersseman P, et al. Invasive pulmonary aspergillosis is a frequent complication of critically ill H1N1 patients: a retrospective study. Intensive care medicine. 2012;38(11):1761-1768.

16. Limper AH, Adenis A, Le T, Harrison TS. Fungal infections in HIV/AIDS. The Lancet Infectious Diseases. 2017;17(11):e334-e343.

17. Wu C, Chen X, Cai Y, et al. Risk factors associated with acute respiratory distress syndrome and death in patients with coronavirus disease 2019 pneumonia in Wuhan, China. JAMA internal medicine. 2020.

18. Arentz M, Yim E, Klaff L, et al. Characteristics and outcomes of 21 critically ill patients with COVID-19 in Washington State. Jama. 2020.

19. Wang D, Hu B, Hu C, et al. Clinical characteristics of 138 hospitalized patients with 2019 novel coronavirus-infected pneumonia in Wuhan, China. Jama. 2020;323(11):1061-1069. 
20. Bhatraju PK, Ghassemieh BJ, Nichols M, et al. Covid-19 in critically ill patients in the Seattle regioncase series. New England Journal of Medicine. 2020.

21. Guan W-j, Ni Z-y, Hu Y, et al. Clinical characteristics of 2019 novel coronavirus infection in China. MedRxiv. 2020.

22. Nyga R, Maizel J, Nseir S, et al. Invasive Tracheobronchial Aspergillosis in Critically Ill Patients with Severe Influenza[J]. Am J Respir Crit Care Med, 2020.

23. Delevaux I, Andre M, Colombier M, et al. Can procalcitonin measurement help in differentiating between bacterial infection and other kinds of inflammatory processes?[J]. Ann Rheum Dis, 2003,62(4):337-340.

24. Hammer S, Meisner F, Dirschedl P, et al. Procalcitonin for differential diagnosis of graft rejection and infection in patients with heart and/or lung grafts[J]. Intensive Care Med, 2000,26 Suppl 2:S182-S186.

25. Wang K, Luo Y, Zhang W, et al. Diagnostic value of Candida mannan antigen and anti-mannan IgG and IgM antibodies for Candida infection. Mycoses. 2020;63(2):181-188.

26. Dobias R, Jaworska P, Tomaskova H, et al. Diagnostic value of serum galactomannan, $(1,3)-\beta$-d-glucan, and Aspergillus fumigatus-specific IgA and IgG assays for invasive pulmonary aspergillosis in non-neutropenic patients. Mycoses. 2018;61(8):576-586.

Table 1 Baseline characteristics of 236 patients

\begin{tabular}{|c|c|c|c|c|}
\hline Characteristics & Total $(n=236)$ & $\begin{array}{l}\text { Serologically } \\
\text { positive } \\
\operatorname{group}(n=80)\end{array}$ & $\begin{array}{l}\text { Serologically } \\
\text { negative } \\
\operatorname{group}(n=156)\end{array}$ & $P$ value \\
\hline Sex & & & & NS. \\
\hline Male & $141(60 \%)$ & $52(65 \%)$ & $89(57 \%)$ & \\
\hline Female & $95(40 \%)$ & $28(35 \%)$ & $67(43 \%)$ & \\
\hline Age & & & & $* * *$ \\
\hline [?]65 years & $45(19 \%)$ & $35(44 \%)$ & $10(6 \%)$ & \\
\hline$>65$ years & $191(81 \%)$ & $45(56 \%)$ & $146(94 \%)$ & \\
\hline Clinical level & & & & NS. \\
\hline general & $28(12 \%)$ & $8(10 \%)$ & $20(13 \%)$ & \\
\hline severe & $157(66 \%)$ & $53(66 \%)$ & $104(67 \%)$ & \\
\hline critical & $51(22 \%)$ & $19(24 \%)$ & $32(21 \%)$ & \\
\hline Host factors & & & & \\
\hline $\begin{array}{l}\text { Malignant blood } \\
\text { disease }\end{array}$ & $3(1 \%)$ & 0 & $3(2 \%)$ & NS. \\
\hline Solid tumors & $20(8 \%)$ & $8(10 \%)$ & $12(8 \%)$ & NS. \\
\hline $\begin{array}{l}\text { Hematopoietic } \\
\text { stem cell } \\
\text { transplantation }\end{array}$ & 0 & 0 & 0 & \\
\hline $\begin{array}{l}\text { Solid organ } \\
\text { transplantation }\end{array}$ & $1(0 \%)$ & 0 & $1(1 \%)$ & NS. \\
\hline HIV & 0 & 0 & 0 & \\
\hline $\begin{array}{l}\text { Hereditary } \\
\text { immune disease }\end{array}$ & 0 & 0 & 0 & \\
\hline $\begin{array}{l}\text { History of } \\
\text { invasive fungal } \\
\text { infection }\end{array}$ & $3(1 \%)$ & $2(3 \%)$ & $1(1 \%)$ & NS. \\
\hline $\begin{array}{l}\text { Splenectomy } \\
\text { Treatment } \\
\text { factors }\end{array}$ & $1(0 \%)$ & 0 & $1(1 \%)$ & NS. \\
\hline
\end{tabular}




\begin{tabular}{lllll}
$\begin{array}{l}\text { Broad-spectrum } \\
\text { antibiotics } \\
\text { therapy }\end{array}$ & $47(20 \%)$ & $23(29 \%)$ & $24(15 \%)$ & $*$ \\
$\begin{array}{l}\text { Glucocorticoids } \\
\text { therapy }\end{array}$ & $32(14 \%)$ & $14(18 \%)$ & $18(12 \%)$ & NS. \\
$\begin{array}{l}\text { Immunosuppressants } \\
\text { Central venous }\end{array}$ & $2(1 \%)$ & $1(1 \%)$ & $1(1 \%)$ & NS. \\
$\begin{array}{l}\text { cannula } \\
\text { Parenteral }\end{array}$ & $22(9 \%)$ & $10(13 \%)$ & $12(8 \%)$ & NS. \\
$\begin{array}{l}\text { nutrition } \\
\begin{array}{l}\text { Invasive ventilator } \\
\text { ICU admission }\end{array}\end{array}$ & $21(9 \%)$ & 0 & $2(1 \%)$ & NS. \\
$\begin{array}{l}\text { Outcome of } \\
\text { hospital stay }\end{array}$ & $44(19 \%)$ & $8(10 \%)$ & $13(8 \%)$ & NS. \\
$\begin{array}{l}\text { Death } \\
\text { Discharge }\end{array}$ & $14(6 \%)$ & $28(18 \%)$ & NS. \\
\hline
\end{tabular}

Table 2 Strains and mortality of 80 positive cases

\begin{tabular}{|c|c|c|c|c|c|}
\hline & Total $(\mathrm{n}=236)$ & $\begin{array}{l}\text { Moderate } \\
(\mathrm{n}=28)\end{array}$ & Severe $(n=153)$ & Critical $(\mathrm{n}=55)$ & $P$ value \\
\hline $\begin{array}{l}\text { Negative } \\
\text { cases }\end{array}$ & $156(66 \%)$ & $20(71 \%)$ & $100(65 \%)$ & $36(65 \%)$ & NS. \\
\hline $\begin{array}{l}\text { Positive } \\
\text { cases }\end{array}$ & $80(34 \%)$ & $8(29 \%)$ & $53(35 \%)$ & $19(35 \%)$ & NS. \\
\hline Only candida & $32(14 \%)$ & $2(7 \%)$ & $23(15 \%)$ & $1(2 \%)$ & * \\
\hline $\begin{array}{l}\text { Only } \\
\text { aspergillus }\end{array}$ & $31(13 \%)$ & $4(14 \%)$ & $21(14 \%)$ & $6(11 \%)$ & NS. \\
\hline $\begin{array}{l}\text { Candida with } \\
\text { aspergillus }\end{array}$ & $17(7 \%)$ & $2(7 \%)$ & $9(6 \%)$ & $12(22 \%)$ & $* *$ \\
\hline $\begin{array}{l}\text { Cryptococcus } \\
\text { neoformans }\end{array}$ & 0 & & 0 & 0 & \\
\hline $\begin{array}{l}\text { Total } \\
\text { mortality }\end{array}$ & $14(6 \%)$ & 0 & $1(1 \%)$ & $13(24 \%)$ & $* * *$ \\
\hline $\begin{array}{l}\text { Mortality of } \\
\text { negative } \\
\text { cases }\end{array}$ & $9(6 \%)$ & 0 & $1(1 \%)$ & $8(22 \%)$ & $* * *$ \\
\hline $\begin{array}{l}\text { Mortality of } \\
\text { positive } \\
\text { cases }\end{array}$ & $5(6 \%)$ & 0 & 0 & $5(26 \%)$ & $* * *$ \\
\hline $\begin{array}{l}\text { Mortality in } \\
\text { only candida } \\
\text { infection }\end{array}$ & 0 & 0 & 0 & 0 & \\
\hline $\begin{array}{l}\text { Mortality in } \\
\text { only } \\
\text { aspergillus } \\
\text { infection }\end{array}$ & $4(5 \%)$ & 0 & 0 & $4(21 \%)$ & $* * *$ \\
\hline $\begin{array}{l}\text { Mortality in } \\
\text { candida with } \\
\text { aspergillus }\end{array}$ & $1(1 \%)$ & 0 & 0 & $1(5 \%)$ & NS. \\
\hline
\end{tabular}


Supplementary table 1 Positive rate of different fungal detection methods

\begin{tabular}{|c|c|c|c|c|c|c|c|}
\hline & $\begin{array}{l}\text { Fungus } \\
\text { culture }\end{array}$ & GM test & $\begin{array}{l}\text { Candida } \\
\text { mannan } \\
\text { test }\end{array}$ & $\begin{array}{l}\text { Atr-IgG } \\
\text { test }\end{array}$ & $\begin{array}{l}\text { Eno-IgG } \\
\text { test }\end{array}$ & GXM test & $\begin{array}{l}\text { Fungus } \\
\text { chip }\end{array}$ \\
\hline $\begin{array}{l}\text { Tested } \\
\text { cases }\end{array}$ & 34 & 164 & 146 & 236 & 236 & 86 & 32 \\
\hline $\begin{array}{l}\text { Suspicious } \\
\text { positive } \\
\text { cases }\end{array}$ & 16 & 10 & 11 & 43 & 41 & 0 & 5 \\
\hline $\begin{array}{l}\text { Suspicious } \\
\text { positive } \\
\text { rate }\end{array}$ & $47 \%$ & $6 \%$ & $8 \%$ & $18 \%$ & $17 \%$ & 0 & $16 \%$ \\
\hline candida & 16 & - & 11 & - & 41 & - & 5 \\
\hline aspergillus & 0 & 10 & - & 43 & - & - & 0 \\
\hline $\begin{array}{l}\text { cryptococcus } \\
\text { neoformans }\end{array}$ & - & - & - & - & - & 0 & 0 \\
\hline
\end{tabular}
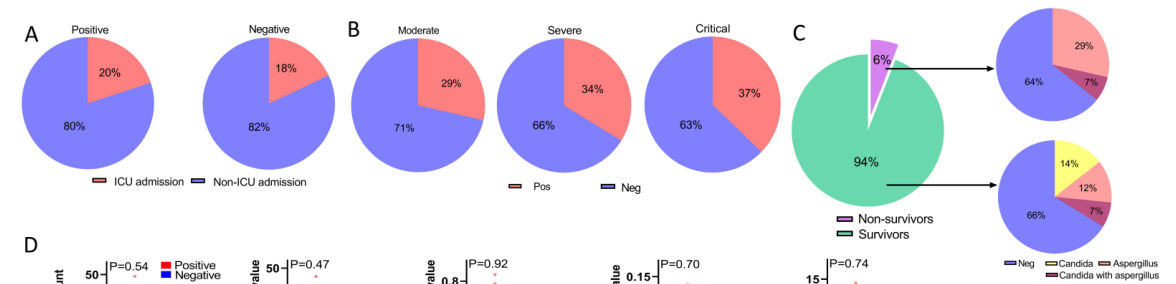

D
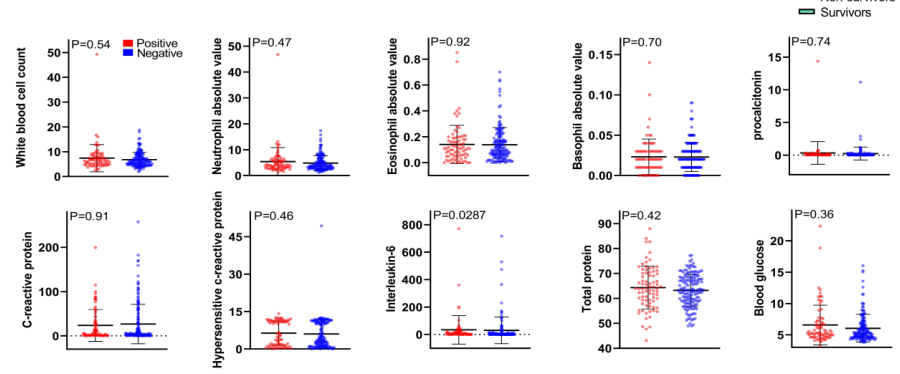

E

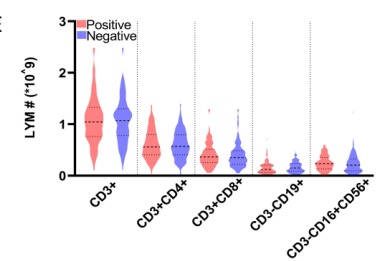

Figure 1. Baseline information and laboratory results between fungal serologically positive and negative groups. (A) Different proportions in moderate, severe, critical levels. (B) Different proportions of ICU admission. (C) Composition of different fungal strains between survivors and non-survivors. (D) Ten laboratory indicators comparison between two groups. (E) Lymphocyte subset results comparison between two groups. 
A

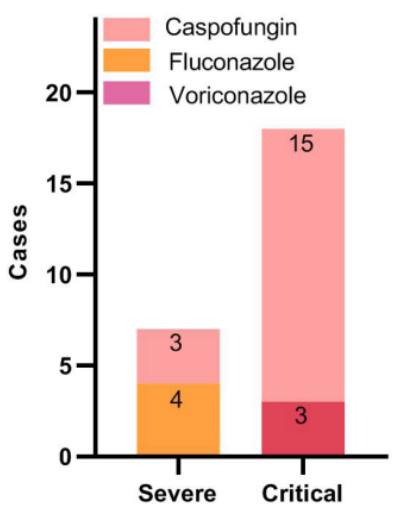

C

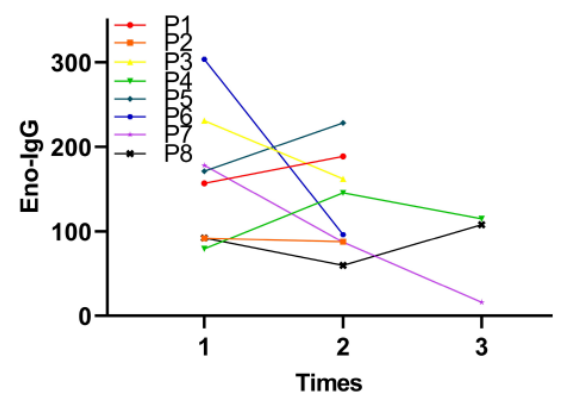

B
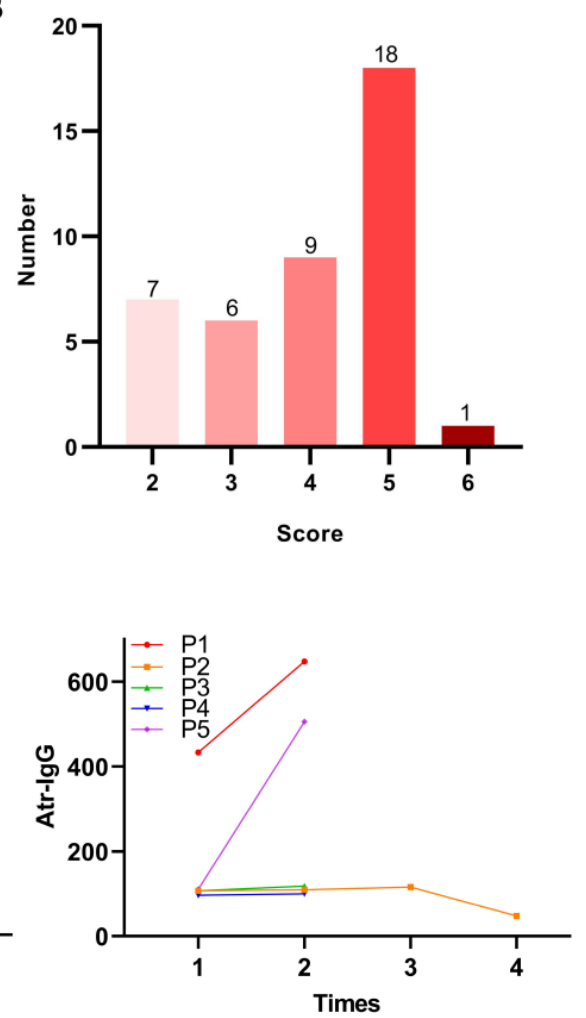

Figure 2. Anti-fungal drug use of 25 patients and serological antibody dynamic changes of several patients. (A) Anti-fungal drug use in 25 patients including caspofungin, fluconazole, voriconazole, and their six-category scale scores. (B) Dynamic changes in Eno-IgG of 8 patients and Atr-IgG of 5 patients.
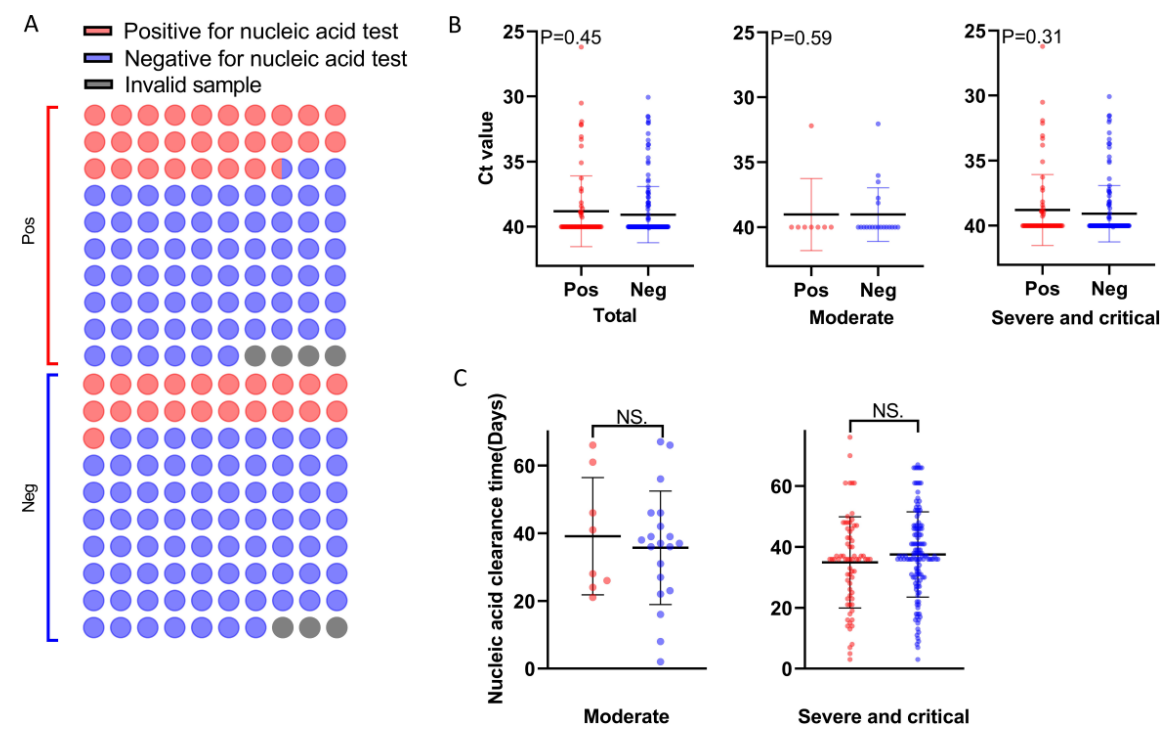

Figure 3. Nucleic acid test results between fungal serologically positive and negative groups. (A) Proportion of positive, negative, and invalid nucleic acid results between two groups. (B) Ct value 
comparison between two groups in moderate, severe and critical levels. (C) Nucleic acid clearance time between two groups in moderate, severe and critical levels.

A

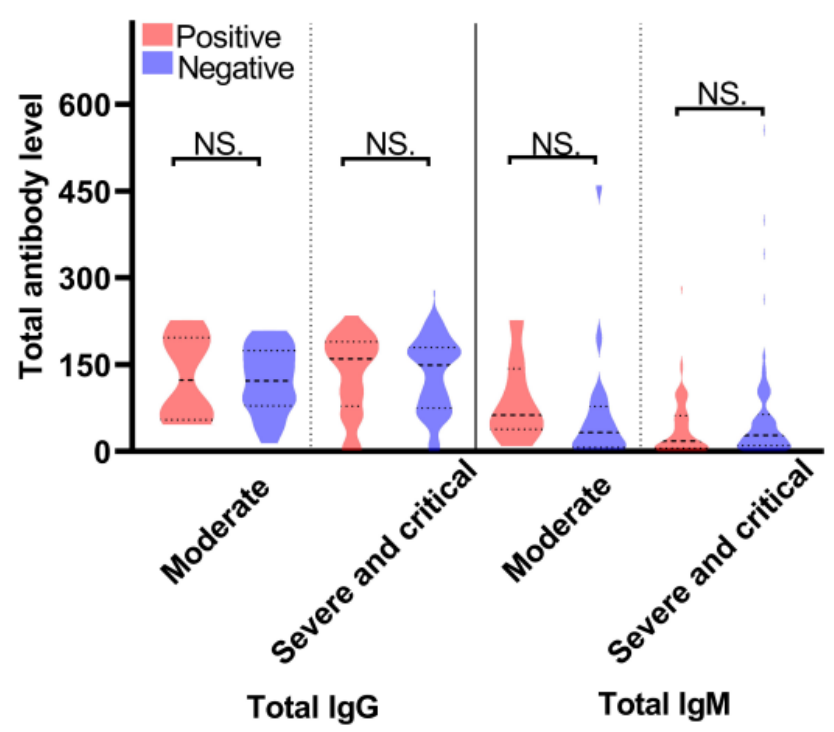

B

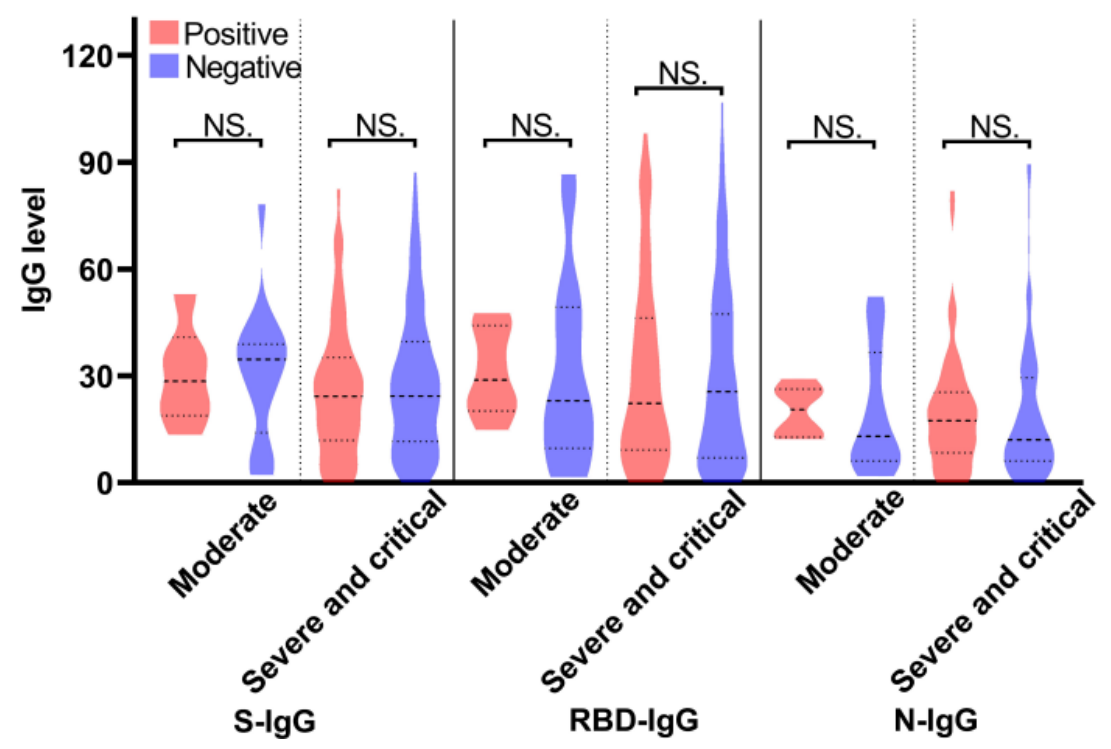

Figure 4. Detection results of total antibody and typing antibody between fungal serologically positive and negative groups. (A) Total IgG and total IgM level between two groups in moderate, severe and critical levels. (B) S-IgG, RBD-IgG, N-IgG level between two groups in moderate, severe and critical levels. NS., no significance. 

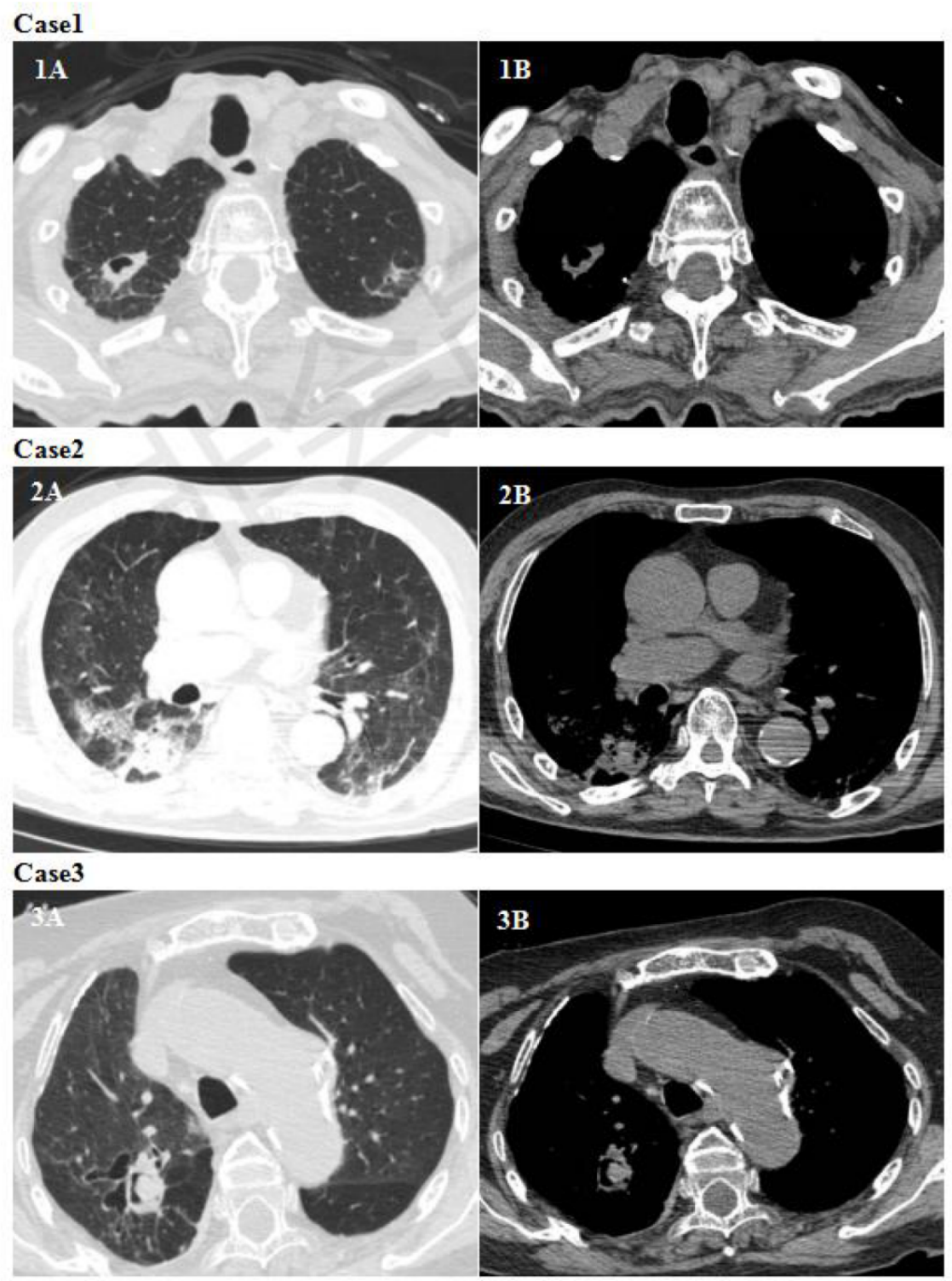

Figure 5. Chest CT of three patients Case 1: chest CT was obtained on Feb 17 (1A, 1B). Male, 86 years old, whose Eno-IgG test and fungus culture presented positive results. Case 2: chest CT obtained on Mar 6 (2A, 2B). Male, 81 years old, whose Atr-IgG test presented two continuous positive results, and received the treatment of antifungal drug voriconazole. Case 3: chest CT obtained on Mar 19 (3A, 3B). Female, 85 years old, two CT examinations in other hospital indicated the possibility of mould pellets. 
A
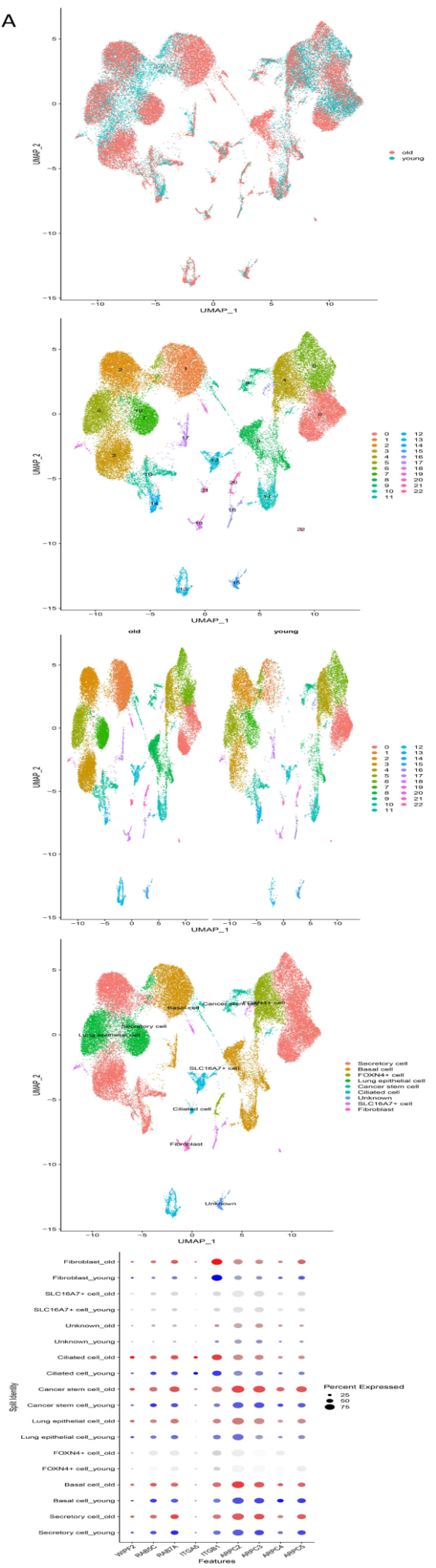
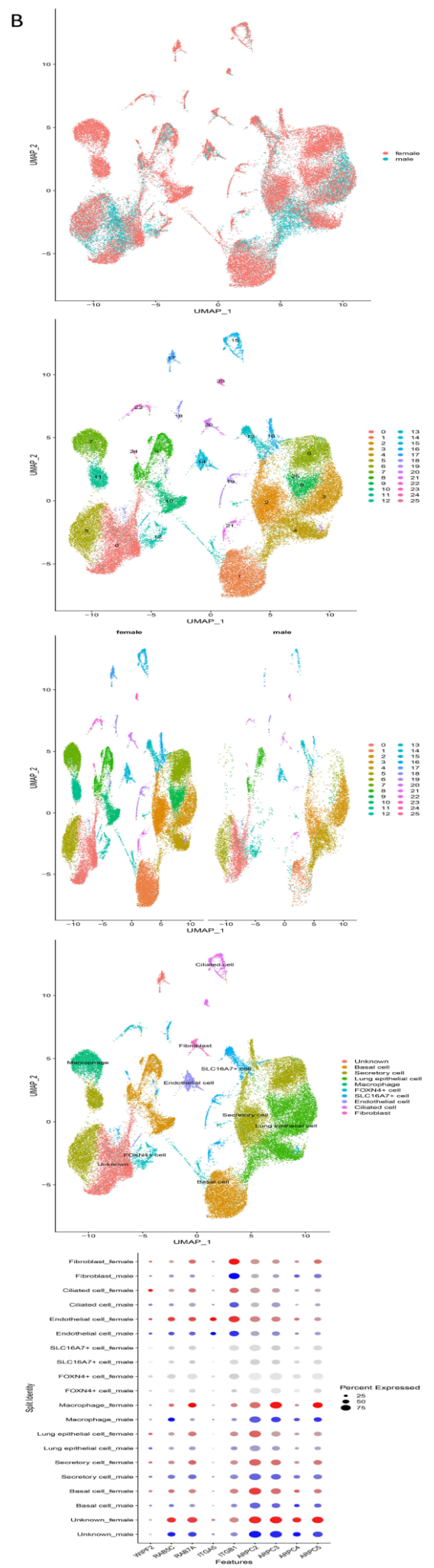

Figure 6. Single-cell RNA seq analysis of eight healthy lungs.(A) Single-cell RNA seq analysis of 
five old people( $>45$ years) and three young ([?]45 years) people. (B) Single-cell RNA seq analysis of six females and two males. 